\title{
Efficacy and mechanisms of traditional Chinese medicine for COVID-19: a systematic review
}

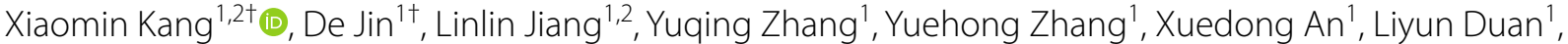 \\ Cunqing Yang ${ }^{1}$, Rongrong Zhou ${ }^{1}$, Yingying Duan ${ }^{1,2}$, Yuting Sun ${ }^{1}$ and Fengmei Lian ${ }^{1 *}$
}

\begin{abstract}
Since the outbreak of coronavirus disease 2019 (COVID-19), traditional Chinese medicine (TCM) has made an important contribution to the prevention and control of the epidemic. This review aimed to evaluate the efficacy and explore the mechanisms of TCM for COVID-19. We systematically searched 7 databases from their inception up to July 21, 2021, to distinguish randomized controlled trials (RCTs), cohort studies (CSs), and case-control studies (CCSs) of TCM for COVID-19. Two reviewers independently completed the screening of literature, extraction of data, and quality assessment of included studies. Meta-analysis was performed using Review Manager 5.4 software. Eventually, 29 RCTs involving 3060 patients and 28 retrospective studies (RSs) involving 12,460 patients were included. The meta-analysis demonstrated that TCM could decrease the proportion of patients progressing to severe cases by $55 \%$ and the mortality rate of severe or critical patients by $49 \%$. Moreover, TCM could relieve clinical symptoms, curtail the length of hospital stay, improve laboratory indicators, and so on. In addition, we consulted the literature and obtained 149 components of Chinese medicinal herbs that could stably bind to antiviral targets or anti-inflammatory or immuneregulating targets by the prediction of molecular docking. It suggested that the mechanisms involved anti-virus, antiinflammation, and regulation of immunity. Our study made a systematic review on the efficacy of TCM for COVID-19 and discussed the possible mechanisms, which provided clinical reference and theoretical basis for further research on the mechanism of TCM for COVID-19.
\end{abstract}

Keywords: Traditional Chinese medicine, Coronavirus disease 2019, COVID-19, Efficacy, Mechanism, Systematic review

\section{Introduction}

Coronavirus disease 2019 (COVID-19) is a globally widespread acute respiratory infection due to infection with 2019 novel coronavirus (2019n-CoV, also named SARS$\mathrm{CoV}-2$ ), which continues to threaten human health and development. However, China has managed to get the

\footnotetext{
*Correspondence: 694397644@qq.com

${ }^{+}$Xiaomin Kang and De Jin are co-first authors and have contributed equally to this study

1 Guang'anmen Hospital, China Academy of Chinese Medical Sciences, Beijing, China
}

Full list of author information is available at the end of the article situation under control through various measures, specifically, traditional Chinese medicine (TCM) performed a significant and indispensable function in fighting the epidemic [1]. Previous studies have shown that TCM could suppress virus entry, replication, and transcription, and reduce the immune disorders and cytokine storm caused by viral infection [2]. Abundant clinical evidence supports that TCM has a significant improvement effect on COVID-19, such as improving lung CT, shortening the conversion time of negative results of the 2019-nCoV nucleic acids tests, alleviating clinical symptoms, and promoting recovery [3]. Previous systematic original author(s) and the source, provide a link to the Creative Commons licence, and indicate if changes were made. The images or other third party material in this article are included in the article's Creative Commons licence, unless indicated otherwise in a credit line to the material. If material is not included in the article's Creative Commons licence and your intended use is not permitted by statutory regulation or exceeds the permitted use, you will need to obtain permission directly from the copyright holder. To view a copy of this licence, visit http://creativecommons.org/licenses/by/4.0/. The Creative Commons Public Domain Dedication waiver (http://creativeco mmons.org/publicdomain/zero/1.0/) applies to the data made available in this article, unless otherwise stated in a credit line to the data. 
reviews that evaluated the effectiveness and safety of TCM for COVID-19 did not systematically appraise the proportion of patients progressing to severe cases and the mortality rate of severe or critical patients, and more importantly, did not divide subgroups based on clinical types [4-6]. The prognosis of COVID-19 patients correlates greatly with the clinical types, and it is not appropriate to put patients with different clinical types together for evaluation. Therefore, this study evaluated the efficacy of TCM for COVID-19 after grouping patients according to their different clinical types.

\section{Methods}

We performed this study in accordance with the PRISMA 2020 statement [7]. The protocol for this review has been registered in PROSPERO (CRD42021269173).

\section{Criteria for considering studies Types of studies}

Randomized controlled trials (RCTs), cohort studies (CSs), and case-control studies (CCSs).

\section{Types of participants}

Participants were patients with a clear diagnosis of COVID-19, aged $\geq 18$ years, regardless of gender and clinical types. We grouped patients according to their clinical types. The classification criteria of clinical types of COVID-19 patients referred to Diagnosis and Treatment Protocol for COVID-19 Patients (Tentative 8th Edition) [8]. The clinical symptoms of mild type patients were mild, and there was no evidence of pneumonia on imaging. Moderate type patients presented fever and respiratory symptoms, and chest radiology suggested pneumonia. Adult COVID-19 patients meeting any of the following were regarded as severe type. (1) Tachypnea, respiratory rate $\geq 30$ breaths/min; (2) At rest, oxygen saturation $\leq 93 \%$ during air suction; (3) Partial pressure of oxygen $(\mathrm{PaO} 2) /$ fraction of inspired oxygen $(\mathrm{FiO} 2) \leq 300 \mathrm{mmHg}(1 \mathrm{mmHg}=0.133 \mathrm{kPa}) ; \mathrm{PaO} 2 /$ FiO2 should be corrected by the following formula in high altitude areas (altitude more than $1000 \mathrm{~m}$ ): $\mathrm{PaO} 2 /$ $\mathrm{FiO} 2 \times[760 /$ atmospheric pressure $(\mathrm{mmHg})]$. (4) Clinical symptoms were gradually worsening, and lung imaging indicated lesion significantly progressed $>50 \%$ within $24 \sim 48$ h. COVID-19 patients meeting one of the following conditions were classified into critical type. (1) Respiratory failure demanding mechanical ventilation; (2) Shock; (3) Combined with other organ failure and demanded intensive monitoring and treatment.

In this review, included patients were subsumed into four groups according to the clinical types of COVID19: mild or moderate types into mild group, severe or critical types into severe group, convalescent type into convalescent group, and unknown type or containing two or more of the above three groups into mixed group.

\section{Types of interventions}

Patients in the intervention/TCM group were treated with TCM or a combination of TCM and conventional Western medicine (CWM). We did not restrict the dosage form of used TCM. Patients in the control/CWM group were treated with CWM (e.g., antiviral treatment, nutritional support, anti-infection treatment).

\section{Types of outcome measures}

\section{Primary outcomes}

(1) Proportion of patients progressing to severe cases.

(2) Mortality rate of severe or critical patients.

Because the outcomes of patients were closely related to clinical types, we used the proportion of patients progressing to severe cases as the primary outcome of mild or moderate patients, and the mortality rate as the primary outcome of severe or critical patients.

\section{Secondary outcomes}

(1) Total effective rate. We defined the total effective rate as the proportion of the total number of patients whose clinical symptoms improve $\geq 30 \%$.

(2) Clinical cure rate. We defined the clinical cure of COVID-19 patients as achieving all of the following conditions: no fever $>3$ days; significant reduction of respiratory symptoms; chest CT images improved markedly; two consecutive negative $2019-\mathrm{nCoV}$ nucleic acids tests (not on the same day).

(3) Lung CT improvement rate. A reduction of $30 \%$ or more in the area of the lesion on the lung CT image was considered to be an improvement in lung CT.

(4) TCM symptom scores. TCM symptom scores were assessed in accordance with The Guidelines for Clinical Research of New Drugs of Traditional Chinese Medicine. None, mild, moderate, and severe of the main symptoms corresponded to $0,2,4$, and 6 points, while none, mild, moderate, and severe of the secondary symptoms corresponded to $0,1,2$, and 3 points. Calculated the total points.

(5) Disappearance rate and disappearance time of main symptoms (fever, cough, fatigue);

(6) Discharge rate and length of hospital stay.

(7) The rate and conversion time of negative 2019$\mathrm{nCoV}$ nucleic acids tests for two consecutive times (not on the same day).

(8) Incidence of adverse events.

(9) Related inflammatory or immune indicators including white blood cell count (WBC), lymphocyte count 
(LYM), lymphocyte percentage (LYM\%), C-reactive protein (CRP), and interleukin 6 (IL-6).

\section{Literature search}

We systematically searched 7 databases including PubMed, EMBASE, Cochrane Library, CNKI (China National Knowledge Infrastructure), CBM (Chinese Biomedical Database), VIP (VIP Information Database), and WanFang Database from their inception up to July 21, 2021, to identify RCTs, CSs, and CCSs of TCM for COVID-19. We referred to the retrieval method of " $\mathrm{P}+\mathrm{I}+\mathrm{S}$ " and searched with "subject words + free words". In addition, we added the specific names of commonly used TCM to the search formula to minimize the problem of missed detection. The search terms included "Medicine, Chinese Traditional", "Traditional Chinese medicine", "Huoxiang Zhengqi", "Lianhua Qingwen", "Qingfei Paidu Decoction", "Toujie Quwen granules", "Hanshiyi Formula", "Coronavirus Disease-19", “COVID-19”, "2019-nCoV Infection”, "SARS-CoV-2 Infection" and so on. The complete search strategy of seven databases was shown in (Additional file 1). In order to obtain as much literature as possible, we also manually searched related articles and clinical studies.

\section{Study screening and data extraction}

The eligibility of retrieved studies was evaluated using the established inclusion and exclusion criteria. The contents of data extraction include first author, publication year, country or region of the patients, sample size, methodological quality, treatment regimen of intervention and control, basic characteristics (age, gender, clinical type) of the included patients, duration of treatment, outcome measures, and adverse events. Studies without detailed information on outcome measures were excluded. Study screening and data extraction were conducted independently by two reviewers, and any differences were settled by discussion or the third reviewer's decision.

\section{Quality assessment}

The quality of RCT was evaluated in accordance with the quality assessment criteria from the Cochrane Handbook [9]. The evaluation included the generation of random sequences, allocation concealment, blinding, completeness of outcome data, selective reporting, and other biases. The quality of CS and CCS were evaluated using the corresponding Newcastle-Ottawa Scale (NOS) [10]. The study was scored based on 8 items in three categories: selection of participants, comparability between study groups, and measurement of exposure factors or results. The total score is 9 points. In our study, articles with a score $\geq 7$ were designated as high-quality articles. The quality assessment of each included study was independently conducted by two reviewers, and any discrepancies were settled by discussion or the third reviewer's decision.

\section{Data analysis}

RevMan5.4 was used to perform statistical analysis on the extracted data of the included studies. The relative risk (RR) and weighted mean difference (WMD) were used to analyze dichotomous data and continuous data with $95 \%$ confidence interval (CI). When the heterogeneity test $\mathrm{I}^{2} \leq 50 \%$, the fixed-effects model was selected for combined analysis, otherwise the random-effects model was used. Evaluation of primary outcome measures and secondary outcome measures was performed separately for each group. Results from RCTs were prioritized when they did not agree with the conclusions drawn from CSs or CCSs.

\section{Results}

\section{Description of studies}

The flow diagram of study screening with reference to PRISMA 2020 statement was summarized in Fig. 1.

We retrieved 585 relevant articles from 7 databases, of which 103 were duplicates, and removed 426 articles because they were reviews, case reports, case series, mechanistic studies, or not associated with TCM for COVID-19 after reading titles and abstracts. We also excluded trials in which the intervention was noninternal treatment of TCM, or the patient did not have a definite diagnosis of COVID-19. After intensive fulltext reading of the remaining 56 articles, 8 articles were eliminated. Among them, the participants of two studies did not meet the convalescent diagnosis or were younger than 18 years old; The study types of two studies were case series or cross-sectional study; The interventions of three studies were different administration time, rather than TCM treatment or integrated TCM and CWM treatment compared with CWM treatment; One study did not have detailed information on outcome measure. In addition, we searched the citations of relevant articles and included 9 eligible studies. Eventually, we included 57 eligible studies, including 29 RCTs [11-39] and 28 retrospective studies (RSs) [40-67].

The details of 29 RCTs and 28 RSs were provided in (Additional files 2 and 3). Of the 29 RCTs, 15 were subsumed into mild group, 1 into severe group, 11 into mixed group, and 2 into convalescent group. Of the 28 RSs, 12 were subsumed into mild group, 7 into severe group, 8 into mixed group, and 1 into convalescent group. The sample size of 29 RCTs ranged from 20 to 295, with 3060 patients altogether. The sample size of 28 RSs ranged from 22 to 8939 , with 12,460 patients altogether. 


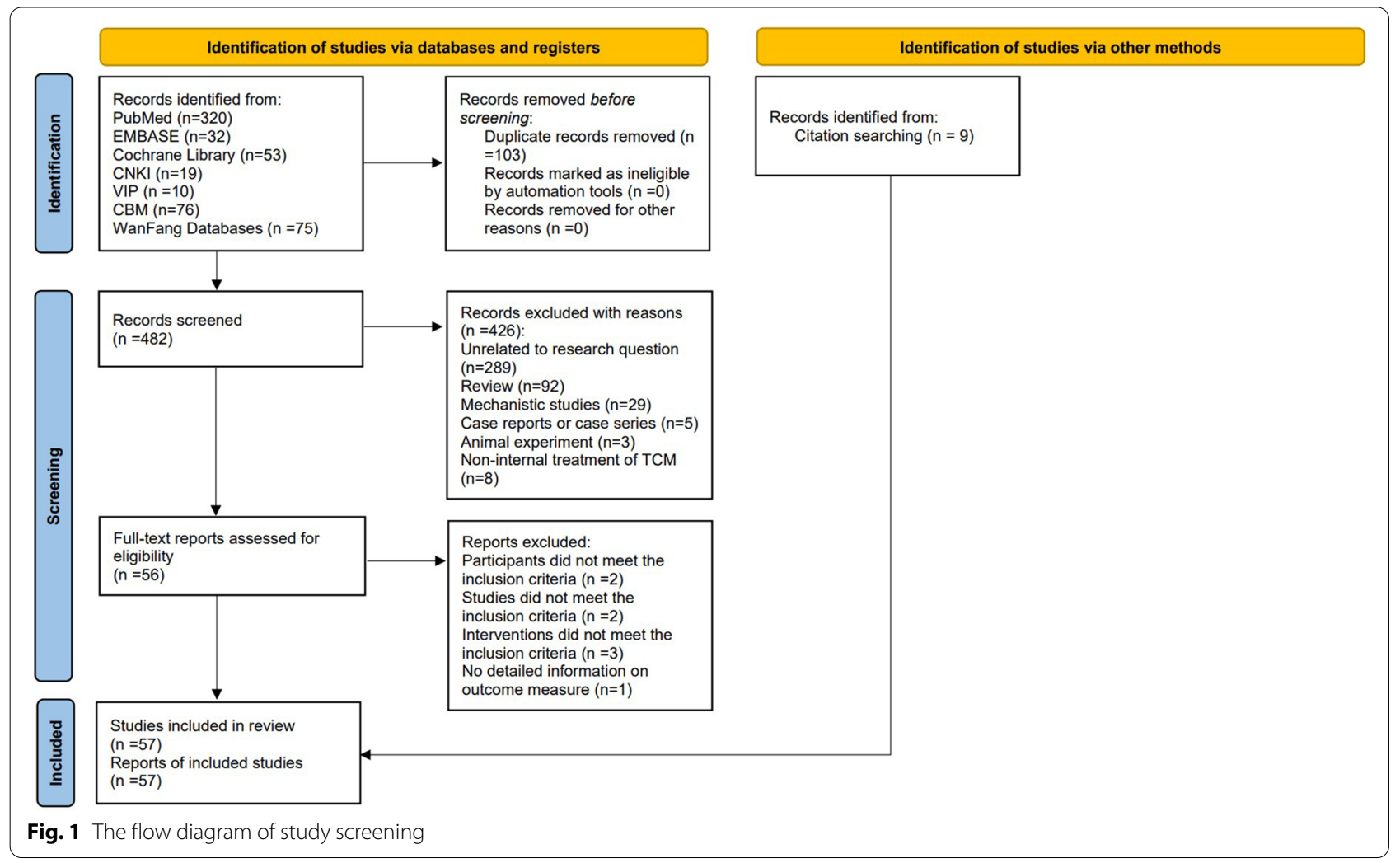

Lianhua Qingwen capsule (or granule) was the most frequently used TCM in the included studies. It was used in 4 RCTs and 4 RSs, with 394 and 230 cases respectively. Qingfei Paidu decoction was the most widely used TCM. It was used by 1 RCT and 3 RSs, with 70 and 2669 users respectively. Other frequently used TCM included Shufeng Jiedu capsule, "Fei Yan No. 1" formula, Huashi Baidu formula, Reduning injection, Shenhuang granule, etc.

\section{Assessment of methodological quality}

Twenty-four RCTs reported the generation of random sequences, of which three RCTs [12, 26, 29] described the performance of allocation concealment. Two RCTs [12, 29] blinded participants and researchers as well as outcome evaluators. Twenty-nine RCTs completely reported the data of each primary outcome, including lost to follow-up and withdrawal. The information described in 29 RCTs could not enable the reviewers to determine whether the study had reporting bias or other potential bias. The methodological quality of 29 RCTs was summarized in Fig. 2.

Since the 28 RSs included were all CSs, the NOS corresponding to CS was used to evaluate their quality. All RSs had quality scores of no less than 7 , of which 16 studies rated 9,11 studies rated 8 , and 1 study rated 7 . Overall, the quality of 28 RSs was high. Details of the methodological quality evaluation of the $28 \mathrm{RSs}$ were provided in (Additional file 4).

\section{Efficacy assessment \\ Proportion of patients progressing to severe cases}

The meta-analysis of 7 RCTs [11, 12, 16, 18, 19, 22, 23] demonstrated that TCM could observably lessen the proportion of patients progressing to severe cases $[R R=0.45$, 95\% CI $\left.(0.29,0.68), \mathrm{I}^{2}=0 \%, \mathrm{P}=0.0002\right]$ (Fig. 3). In addition, 6 RSs [40, 42, 44, 47-49] evaluated this proportion and reached the same conclusion $[R R=0.26,95 \% \mathrm{CI}$ $\left.(0.15,0.46), \mathrm{I}^{2}=0 \%, \mathrm{P}<0.00001\right]$ (Fig. 4). Both RCTs and RSs confirmed that TCM could decrease the proportion of patients progressing to severe cases by more than $55 \%$.

\section{Mortality rate of severe or critical patients}

A high-quality RCT [26] we included indicated that the mortality rate of severe or critical patients in TCM group was visibly lower compared with CWM group [38.6\% (22/57) vs $75.9 \%(41 / 54), \mathrm{RR}=0.51,95 \% \mathrm{CI}(0.35,0.73)$, $\mathrm{P}=0.0002]$. Five $\mathrm{RSs}[52,54,55,57,58]$ reached the same conclusion $\left[R R=0.47,95 \%\right.$ CI $(0.31,0.70), I^{2}=54 \%$, $\mathrm{P}=0.0002]$ (Fig. 5). In summary, TCM could decrease the mortality rate of severe or critical patients by more than $49 \%$. 
Random sequence generation (selection bias)

Allocation concealment (selection bias)

Blinding of participants and personnel (performance bias)

Blinding of outcome assessment (detection bias)
Incomplete outcome data (attrition bias)
Selective reporting (reporting bias)
Other bias

Blinding of outcome assessment (detection bias)
Incomplete outcome data (attrition bias)
Selective reporting (reporting bias)
Other bias

Blinding of outcome assessment (detection bias)
Incomplete outcome data (attrition bias)
Selective reporting (reporting bias)
Other bias

Blinding of outcome assessment (detection bias)
Incomplete outcome data (attrition bias)
Selective reporting (reporting bias)
Other bias

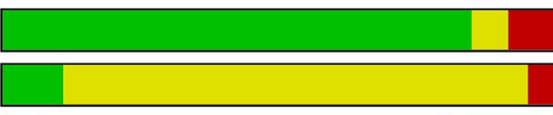

Low risk of bias

Unclear risk of bias

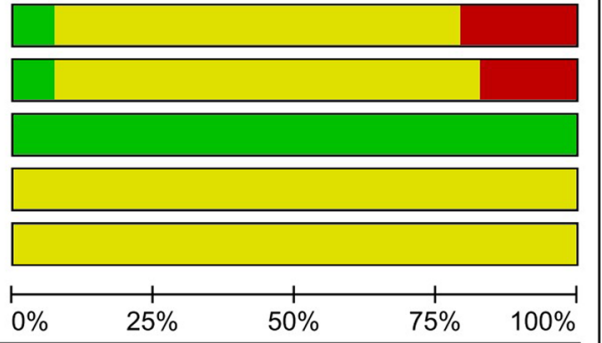

High risk of bias

Fig. 2 The methodological quality of $29 R C T s$

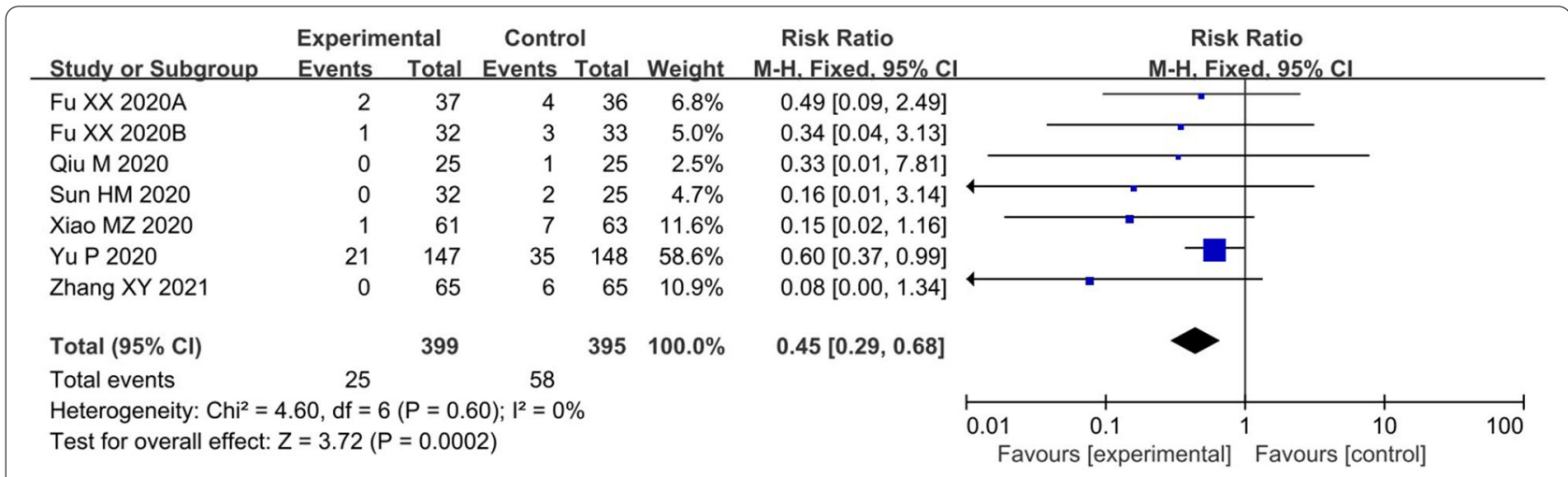

Fig. 3 Primary outcome (1) in RCTs

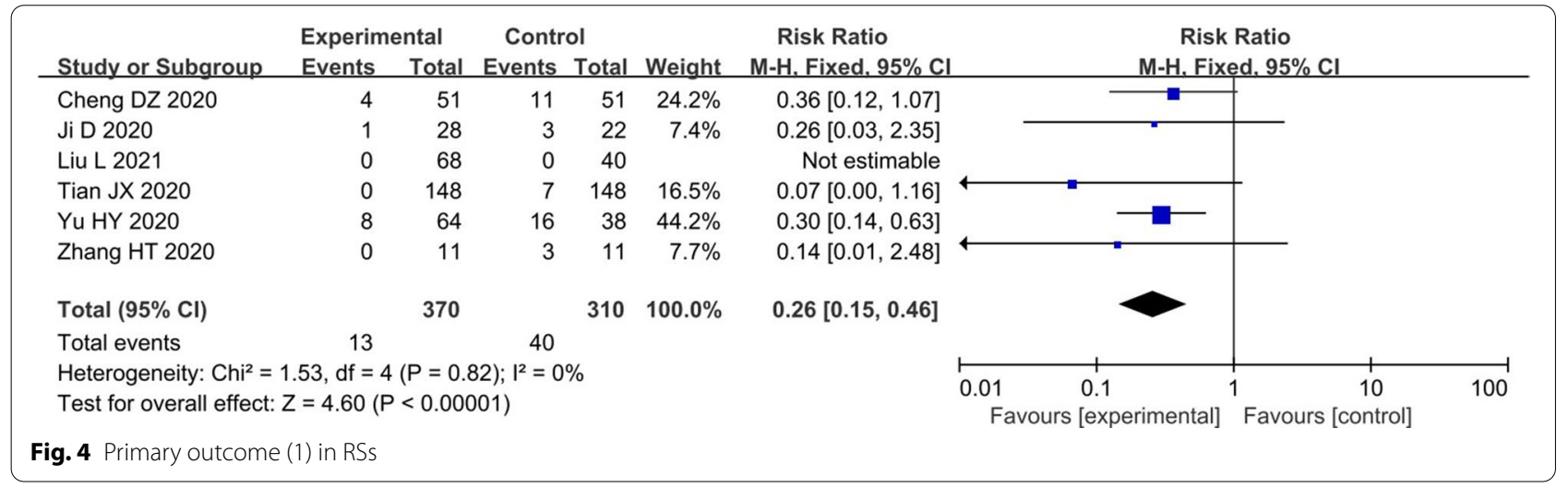

\section{Secondary outcomes}

Efficacy assessment of secondary outcomes was summarized in (Additional file 5).

Meta-analysis indicated that TCM could enhance the total effective rate by $18 \%$, clinical cure rate by $26 \%$, and lung CT improvement rate by $19 \%$. Applying TCM could reduce TCM symptom scores by more than 2.75 points. The discrepancy in the disappearance rate of fever was not statistically significant, but the disappearance time of fever could be shortened by more than 1.05 days in 


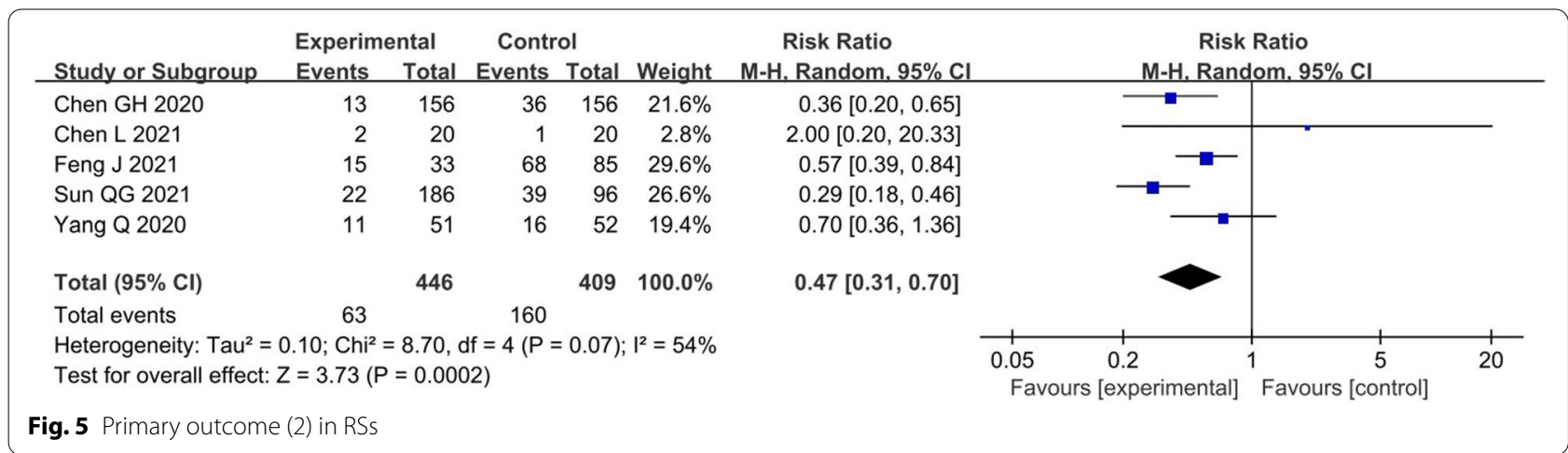

the TCM group compared with the CWM group. TCM could enhance the disappearance rate of cough by more than $33 \%$ and disappearance rate of fatigue by more than $28 \%$, but the difference in the disappearance time of cough and fatigue was not statistically significant. TCM could enhance the discharge rate by $33 \%$ and shorten the length of hospital stay by 3.07 days, especially in severe or critical cases. In addition, TCM could increase the rate of negative $2019-\mathrm{nCoV}$ nucleic acids tests by $37 \%$, and shorten the conversion time of negative 2019-nCoV nucleic acids tests by more than 1.58 days. The results of RSs showed that the incidence of adverse events in TCM group was $82 \%$ of that in CWM group, but the difference did not reach statistical significance in RCTs. However, it was not observed that TCM increased the incidence of serious adverse events in COVID-19 patients, on the contrary, it has been shown that applying TCM could reduce the incidence of serious adverse events in severe or critical cases [98.1\% (53/54) vs 78.9\% (45/57), $\mathrm{P}=0.002$ ] [26]. Applying TCM could increase WBC by $0.25 \times 10^{9} / \mathrm{L}$ and LYM by $0.23 \times 10^{9} / \mathrm{L}$. In addition, TCM could decrease CRP by $7.65 \mathrm{mg} / \mathrm{L}$ and IL-6 by $4.81 \mathrm{ng} / \mathrm{L}$. The difference in LYM\% between TCM and CWM group did not reach statistical significance.

\section{Publication bias}

We made funnel plots for the two primary outcomes. The asymmetry of the three funnel plots suggested that the study might have a moderate publication bias (Fig. 6). We considered that this might be related to the small number and sample size of the included studies.

\section{Discussion}

\section{Common formulas for COVID-19}

Of the prescriptions used in 57 studies, seven formulas were more commonly used. Lianhua Qingwen Capsule was developed by Academician Yiling Wu in 2003 in order to combat severe acute respiratory syndrome by referring to the ancient Chinese prescriptions Maxing shigan Decoction and Yinqiao Powder. In recent years, it has been widely used in the treatment of various viral influenza [68]. Qingfei Paidu Decoction was innovated by Youwen Ge, a distinguished researcher of China Academy of Chinese Medical Sciences, according to the core pathogenesis of COVID-19 and the prescriptions in Treatise on Cold Damage Diseases, including Maxing Shigan Decoction, Shegan Mahuang Decoction, Xiaochaihu Decoction, Wuling Powder, etc. [69]. Shufeng Jiedu Capsule was a Chinese patent medicine made by Hunan Medical University by improving the ancestral secret prescription "Qudu powder" of Tujia Nationality in Western Hunan Province, China. Shufeng Jiedu Capsule was approved by China food and Drug Administration in 2009, and then widely used as antiviral, antibacterial, antitumor and anti-inflammatory drugs [70]. Reduning injection, made from Lonicerae Japonicae Flos (金银花), Artemisiae Annuae Herba (青蒿), and Gardeniae Fructus (㭛子), was approved by China Food and Drug Administration in 2005 and has been shown to have antibacterial, antiviral, antipyretic and antipyretic effects [71]. "Pneumonia No.1 Formula", Huashi Baidu Formula, Shenhuang Granule and other drugs were new prescriptions developed by TCM experts for the treatment of COVID19 based on their many years of clinical experience and combined with the clinical characteristics of COVID-19 [69].

\section{Common herbs for COVID-19}

According to the frequency statistics of the Chinese medicinal herbs used in 57 included studies, we obtained 99 herbs that appeared twice or more. The details were shown in (Additional file 6). The 20 most frequently used herbs were Glycyrrhizae Radix et Rhizoma (甘草), Armeniacae Semen Amarum (苦杏仁), Ephedrae Herba (麻 黄), Gypsum fibrosum (石膏), Poria (获苓), Forsythiae Fructus (连尧), Scutellariae Radix (黄芩), Pinelliae Rhizoma Praeparatum (法牛夏), Pogostemonis Herba (广藿 香), Lonicerae Japonicae Flos (金银花), Bupleuri Radix ( 


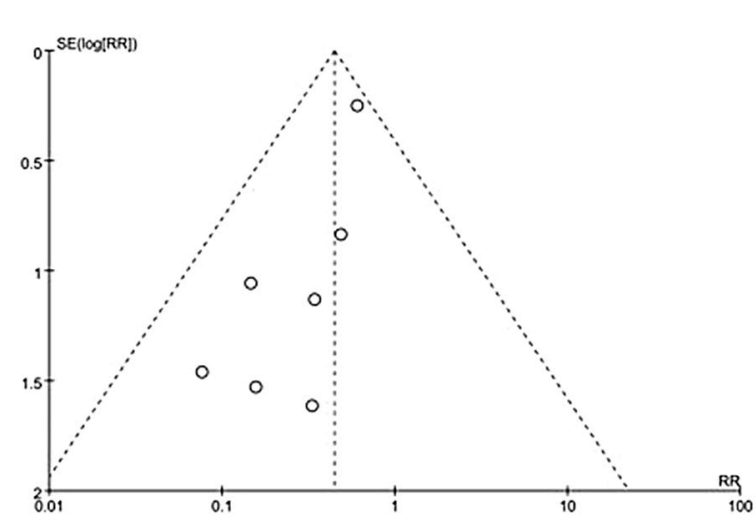

(a)

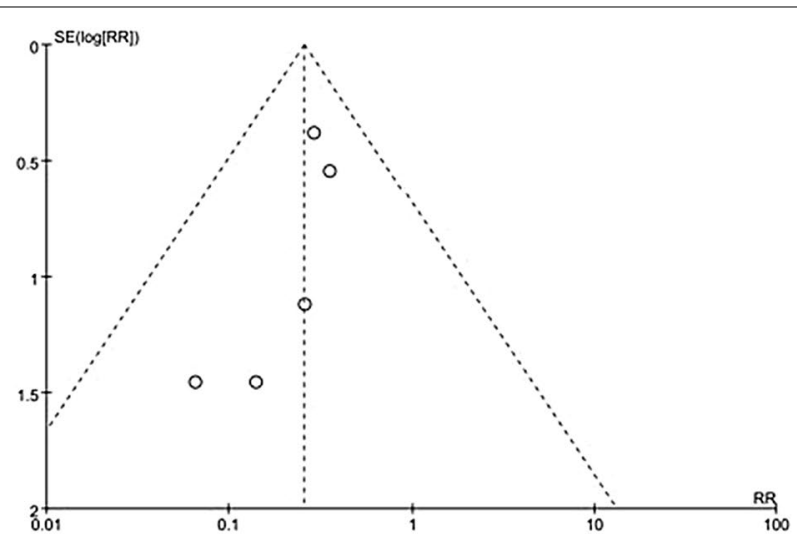

(b)

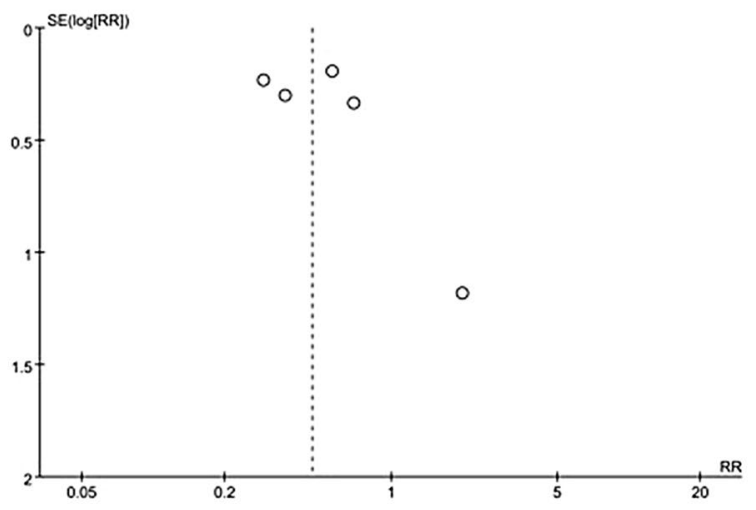

(c)

Fig. 6 Funnel plots of primary outcomes

柴胡), Citri Reticulatae Pericarpium (陈皮), Atractylodis Macrocephalae Rhizoma (白术), Rhei Radix et Rhizoma ( 大黄), Magnoliae Officinalis Cortex (厚朴), Isatidis Radix (板蓝根), Tsaoko Fructus (草果), Menthae Haplocalycis Herba (薄荷), Zingiberis Rhizoma Recens (生姜) and Dryopteridis Crassirhizomatis Rhizoma (绵马贯众).

\section{Core components and targets for COVID-19}

In addition, we reviewed the literature and sorted out the components and targets of TCM for COVID-19 predicted by molecular docking. According to the mechanism of action, the targets were divided into antiviral targets and anti-inflammatory or immune-regulating targets. Antiviral targets included ACE2, 3CLpro, Spro, Plpro, Rdrp, and Nsp14. Anti-inflammatory or immuneregulating targets included IL-6, TNF, IL1B, CCL2, and AKT1.

We predicted that 149 components had therapeutic effects on COVID-19 by molecular docking, of which 20 components had good docking scores not only with antiviral targets but also with anti-inflammatory or immune-regulating targets. The 20 components were formononetin, naringenin, bicuculline, luteolin, quercetin, astragaloside IV, kaempferol, isoquercitrin, rutin, beta-carotene, salvigenin, indirubin, baicalein, calycosin, artemetin, wogonin, rosmarinic acid, apigenin, 7-methoxy-2-methyl isoflavone and emodin [72-94]. The details of components and targets were shown in Additional files 7 and 8$]$.

\section{Antiviral targets}

Studies suggested that 2019-nCoV infection was initiated through the combination of virus with host cell surface receptor ACE2 (angiotensin converting enzyme 2), fusion of virus with cell membrane, and release of virus genome into cells. Among them, Spro (viral spike protein) mediated the activity of receptor binding and membrane fusion [95, 96]. 3CLpro (3C-like protease) in coronaviruses played a vital role in advancing the polyprotein translated from viral RNA [97]. RdRp (RNA-dependent RNA polymerase) was essential for coronavirus replication and transcription and might be a primary target for antiviral drugs [98]. Viral Plpro (papain-like cysteine protease) was considered an important target of antiviral 
drugs because it was required for SARS-CoV-2 replication and could promote the dysregulation of signaling cascades in infected cells [99]. Nsp14 (nonstructural protein 14) was a functional enzyme related to replication fidelity and involved in mRNA capping, which played an essential role in virus replication [100].

\section{Anti-inflammatory or immune-regulating targets}

It has been suggested that a proportion of severe COVID-19 patients might suffer from cytokine storm syndrome and might die because of high inflammation driven by the virus [101]. IL-6 (interleukin-6) was an important cytokine with a variety of physiological functions, including regulating immune cell proliferation and differentiation [102]. IL1B (interleukin 1 beta) was considered an essential pro-inflammatory cytokine related to the origination and development of acute respiratory distress syndrome (ARDS) [103]. TNF (tumor necrosis factor) was regarded as a primary inflammatory cytokine that could drive cytokine production, cell survival, or cell death [104]. CCL2 [Chemokine (C-C motif) ligand 2] exhibited a chemotactic activity for monocytes and was one of the key chemokines regulating monocyte/macrophage migration and infiltration [105]. Severe COVID-19 manifested as ARDS with elevated pro-inflammatory cytokines, involving TNF- $\alpha$, IL-6, IL1B, and CCL2. Therefore, the treatment related to anti-cytokine or anti-cytokine-signaling would be conducive to the prognosis of COVID-19 [106]. Akt1 was one of 3 related serine/threonine-protein kinases implicated in pulmonary fibrosis and lung injury and also played an essential role in immune cell modulation [72].

\section{Core components}

It has been confirmed that four flavonoids including formononetin, apigenin, luteolin, and kaempferol had in vitro activities against enterovirus 71 infection due to reducing viral replication and protein synthesis [107]. Studies suggested that naringenin might be a promising treatment strategy against COVID-19 due to its antiviral and anti-inflammatory effects [108]. Bicuculline showed in vitro anti-inflammatory activity and attenuated inflammation by decreasing the generation of pro-inflammatory cytokines, like IL1B and TNF- $\alpha$, and promoting the production of the anti-inflammatory cytokine interleukin-10 $[109,110]$. Quercetin manifested antiviral, anti-inflammatory, and immune-enhancing effects in vitro and some animal models [111]. Astragaloside IV could improve immunologic function of RAW264.7 cells through stimulating the NF-kB/MAPK signaling pathway [112]. Isoquercitrin could inhibit herpes simplex virus-1 replication to exhibit an antiviral effect [113]. Rutin exerted the antiviral effect mainly by inhibiting or modifying various viral proteins such as viral neuraminidase and DNA/RNA polymerase [114]. Beta-Carotene exerted anti-inflammatory activity through suppressing the production and expression of inflammatory mediators in lipopolysaccharide-stimulated RAW264.7 cells and macrophages [115]. Rosmarinic acid and salvigenin had anti-inflammatory activity, and the mechanisms included inhibiting the maturation and release of IL-1 $\beta$ [116]. Indirubin exhibited potent anti-inflammatory activity and could significantly downregulate the generation of IL-6, IL1B, and TNF- $\alpha$ [117]. It has been shown that baicalein exerted anti-H5N1 effects through inhibiting the replication of the influenza $\mathrm{H} 5 \mathrm{~N} 1$ virus and interfering with the H5N1-induced production of IL- 6 and TNF- $\alpha$ in macrophages [118]. Studies suggested that calycosin could diminish the levels of TNF- $\alpha$, IL- 6 , and IL1B in mice with acute pancreatitis [119]. Artemetin exhibited evident anti-inflammatory activity in many experimental models in rats [120]. Wogonin exerted antiviral effects against herpes simplex virus (HSV) infection by inhibiting viral replication, mRNA transcription, and protein synthesis [121]. 7-Methoxy-2-methyl isoflavone might exert therapeutic effect on COVID-19 through inhibiting inflammatory storms and modulating immune function [90]. Emodin had anti-inflammatory, antiviral, and antibacterial effects, and the anti-inflammatory had been confirmed in various inflammatory models, including asthma, arthritis, and pancreatitis [122].

\section{Advantages and disadvantages of TCM for COVID-19}

TCM has been used to treat epidemic diseases in China for thousands of years. Our study including 29 RCTs and 28 RSs systematically evaluated the efficacy of TCM in treating COVID-19. The results demonstrated that applying TCM treatment could evidently decrease the proportion of patients progressing to severe cases and the mortality rate of severe or critical patients. Moreover, our analysis indicated that the results of total effective rate, clinical cure rate, lung CT improvement rate, TCM symptom scores, disappearance time of fever, disappearance rate of cough and fatigue, discharge rate, length of hospital stay, the rate and conversion time of negative 2019-nCoV nucleic acids tests, incidence of adverse events, LYM, CRP and IL-6 in TCM group were better compared to CWM group.

TCM for COVID-19 had the characteristics of multiple components and multiple targets, which played a role from multiple aspects and had important therapeutic significance throughout the disease. However, TCM also had certain disadvantages. For example, TCM formulas had many components and targets, and were not targeted 
when exerting therapeutic effect, so it was difficult to elaborate its mechanism in depth.

\section{Differences from previous meta-analyses of TCM for COVID-19}

In addition, it is worth noting that the prevention and treatment goals for different clinical types of patients with COVID-19 are different. For mild or moderate types patients, reducing the proportion progressing to severe cases is the main goal. For severe or critical patients, reducing mortality rate is the main goal. For convalescent type patients, reducing the positive RT-PCR test results and alleviating clinical symptoms is the main goal [123]. At present, the published systematic reviews of TCM for COVID-19 have not classified patients according to the clinical types, and this review systematically appraised the treatment of TCM in different clinical types of COVID-19 for the first time.

In our study, the primary outcomes were generally recognized and reasonable. The study participants were grouped according to clinical types. Moreover, we included not only RCTs but also RSs, which confirmed the efficacy of TCM for COVID-19 from different angles and levels. Furthermore, our study conducted a systematic literature review on the mechanism of TCM for COVID-19 based on 57 included studies.

\section{Limitations and perspective}

However, this review also has some limitations. Firstly, the quality of some included studies is not high or the sample size is small, so bias is prone to occur. Secondly, due to the need for grouping evaluation based on clinical types, the number of included studies is still relatively small. Thirdly, there are too few clinical studies in the recovery period to see the long-term effects of TCM for COVID-19. Fourthly, in terms of mechanism, most researches focus on network pharmacology and cell level, and there is too little evidence at the animal level and organizational level. Therefore, more high-quality and large-sample RCTs are demanded to assess the efficacy of TCM for COVID-19, and more animal experiments are required to verify the efficacy.

The epidemic of COVID-19 is still rampant worldwide, and the pace of virus mutation has not stopped. It is still necessary to find effective drugs against COVID19 , and we believe that TCM is a module worthy of further research in the treatment of COVID-19. Our study made a more systematic review on the efficacy of TCM for COVID-19 and discussed the possible mechanisms, which provided clinical reference and theoretical basis for further research on the mechanism of TCM for COVID-19.

\section{Conclusion}

TCM had a definite therapeutic effect on COVID19. Especially, TCM could decrease the proportion of patients progressing to severe cases by $55 \%$ and the mortality rate of severe or critical patients by $49 \%$. Furthermore, the mechanism was explored, and it was concluded that TCM played a therapeutic role in COVID-19 mainly through anti-virus, anti-inflammation, and regulation of immunity.

\section{Abbreviations \\ 2019n-CoV: 2019 Novel coronavirus; 3CLpro: 3C-like protease; ACE2: Angio- tensin converting enzyme 2; ARDS: Acute respiratory distress syndrome; CCL2: Chemokine ( $C-C$ motif) ligand 2; CCSs: Case-control studies; Cl: Confidence interval; COVID-19: Coronavirus disease 2019; CRP: C-reactive protein; CSs: Cohort studies; CWM: Conventional Western medicine; FiO2: Fraction of inspired oxygen; IL1B: Interleukin 1 beta; LL-6: Interleukin 6; LYM\%: Lymphocyte percentage; LYM: Lymphocyte count; Nsp14: Nonstructural protein 14; PaO2: Partial pressure of oxygen; Plpro: Papain-like protease; RCTs: Randomized controlled trials; RdRp: RNA-dependent RNA polymerase; RR: Relative risk; RSs: Retrospective studies; SARS-CoV-2: Severe acute respiratory syndrome coronavirus 2; Spro: Spike protein; TCM: Traditional Chinese medicine; TNF: Tumor necrosis factor; WBC: White blood cell count; WMD: Weighted mean difference.}

\section{Supplementary Information}

The online version contains supplementary material available at https://doi. org/10.1186/s13020-022-00587-7.

Additional file 1. Search strategy of seven databases.

Additional file 2. Basic characteristics of included RCTs.

Additional file 3. Basic characteristics of included retrospective studies.

Additional file 4. The quality of the included retrospective studies.

Additional file 5. Efficacy assessment of secondary outcomes.

Additional file 6. The frequency of the Chinese medicinal herbs.

Additional file 7. Antiviral components and targets.

Additional file 8. Anti-inflammatory or immune-regulating components and targets.

\section{Acknowledgements}

Not applicable.

\section{Authors' contributions}

FL designed this study, YZ (Yuqing Zhang) and YZ (Yuehong Zhang) ran the search strategy, XA and LD extracted data, CY and RZ conducted statistical analysis, YD and YS produced pictures and tables, DJ and LJ sorted out the mechanism part, and XK wrote the manuscript. All authors read and approved the final manuscript.

Funding

This study was supported by the Traditional Chinese Medicine Special Project for COVID-19 Emergency of National Administration of Traditional Chinese Medicine (2020ZYLCYJ04-1).

\section{Availability of data and materials}

The datasets used and/or analysed during the current study are available from the corresponding author on reasonable request. 


\section{Declarations}

Ethics approval and consent to participate

Not applicable.

\section{Consent for publication}

Not applicable.

\section{Competing interests}

The authors declare that they have no competing interests.

\section{Author details}

${ }^{1}$ Guang'anmen Hospital, China Academy of Chinese Medical Sciences, Beijing, China. ${ }^{2}$ Beijing University of Chinese Medicine, Beijing, China.

Received: 20 January 2022 Accepted: 22 February 2022

Published online: 28 February 2022

\section{References}

1. Zhao Z, Li Y, Zhou L, et al. Prevention and treatment of COVID-19 using traditional Chinese medicine: a review. Phytomedicine. 2021;85:153308.

2. An $X$, Zhang $Y$, Duan $L$, et al. The direct evidence and mechanism of traditional Chinese medicine treatment of COVID-19. Biomed Pharmacother. 2021;137:111267.

3. An X, Duan L, Zhang YH, et al. The three syndromes and six Chinese patent medicine study during the recovery phase of COVID-19. Chin Med. 2021;16:44.

4. Liu M, Gao Y, Yuan Y, et al. Efficacy and safety of integrated traditional Chinese and western medicine for Corona Virus Disease 2019 (COVID-19): a systematic review and meta-analysis. Pharmacol Res. 2020;158:104896.

5. Xiong X, Wang P, Su K, et al. Chinese herbal medicine for coronavirus disease 2019: a systematic review and meta-analysis. Pharmacol Res. 2020;160:105056.

6. Jiang $F, X u N$, Zhou Y, et al. Contribution of traditional Chinese medicine combined with conventional western medicine treatment for the novel coronavirus disease (COVID-19), current evidence with systematic review and meta-analysis. Phytother Res. 2021;35(11):5992-6009.

7. Page MJ, McKenzie JE, Bossuyt PM, et al. The PRISMA 2020 statement: an updated guideline for reporting systematic reviews. BMJ. 2021:372:71.

8. National Health Commission of the People's Republic of China. Diagnosis and Treatment Protocol for COVID-19 Patients (Tentative 8th Edition). http://en.nhc.gov.cn/2020-09/07/c_81565.htm Accessed 20 July 2021

9. Higgins JP, Altman DG, Gotzsche PC, Juni P, Moher D, Oxman AD, et al. The Cochrane collaboration's tool for assessing risk of bias in randomised trials. BMJ. 2011:343:d5928.

10. Liu SD, Chen WT, Chi CC. Association between medication use and bullous pemphigoid: a systematic review and meta-analysis. JAMA Dermato. 2020;156:891-900.

11. Xiao M, Tian J, Zhou Y, Xu X, Min X, Lv Y, et al. Efficacy of Huoxiang Zhengqi dropping pills and Lianhua Qingwen granules in treatment of COVID-19: a randomized controlled trial. Pharmacol Res. 2020;161:105126

12. Zhang $X Y, L v L$, Zhou $Y L, X i e ~ L D, X u ~ Q, Z o u X F$, et al. Efficacy and safety of Xiyanping injection in the treatment of COVID-19: a multicenter, prospective, open-label and randomized controlled trial. Phytother Res. 2021;35:4401-10.

13. Shi N, Guo L, Liu B, Bian Y, Chen R, Chen S, et al. Efficacy and safety of Chinese herbal medicine versus Lopinavir-Ritonavir in adult patients with coronavirus disease 2019: a non-randomized controlled trial. Phytomedicine. 2021;81:153367.

14. Duan C, Xia WG, Zheng CJ, Sun GB, Li ZL, Li QL, et al. Clinical observation on Jinhua Qinggan granule combined with conventional western medicine therapy in treating mild cases of coronavirus disease 2019. J Tradit Chin Med. 2020;61:1473-7.
15. He Q, Zhang QJ, Gan XW, Li XG. Clinical analysis of Buzhong Yiqi decoction in treating mild cases of coronavirus disease 2019. J Emerg Tradit Chin Med. 2021:30:385-7.

16. Fu XX, Lin LP, Tan XH. Clinical study on 37 cases of COVID-19 treated with integrated traditional Chinese and western medicine. Tradit Chin Drug Res Clin Pharmacol. 2020;31:600-4.

17. Liu W, Su XY, Liao XL. Effect of antiviral drugs combined with traditional Chinese medicine on mild cases of coronavirus disease 2019. Contemp Med Symp. 2021:19:159-60.

18. Qiu M, Li QT, Zhu DP, Wang CH, Sun QZ, Qian CF, et al. Efficacy observation of Maxing Xuanfei Jiedu decoction on moderate COVID-19. J Emerg Tradit Chin Med. 2020;29:1129-30.

19. Sun HM, Xu F, Zhang L, Wei C, Chen JY, Wang QX, et al. Study on clinical efficacy of Lianhua Qingke granule in treatment of mild and ordinary COVID-19. Chin J Exp Tradit Med Formulae. 2020;26:29-34.

20. Wang L, Xu M, Wang Y, Li HB, Liu N, Zuo JL. Clinical study on Shengmai powder combined with Shenlingbaizhu powder in the treatment of common coronavirus disease 2019. China J Tradit Chin Med Pharm. 2020;35:4268-71.

21. Wang Y, Chen L, Zheng L, Ku BQ, Yu R, Zhang XF. Clinical effects of Qingfei Paidu decoction combined with conventional treatment on patients with coronavirus disease 2019. Chin Tradit Patent Med. 2021;43:656-9.

22. Yu P, Li YZ, Wang SB, Wang Y. Effect of Lianhua Qingwen Granules plus abidol on treatment of mild coronavirus disease 2019. Chin Pharm J. 2020:55:1042-5.

23. Fu XX, Lin LP, Tan XH. Clinical observation on effect of Toujie Quwen granules in treatment of COVID-19. Chin J Exp Tradit Med Formulae. 2020;26:44-8.

24. Xiao Q, Jiang YJ, Wu SS, Wang Y, An J, Xu WP, et al. Analysis of the value of Shufeng Jiedu capsule combined with abidol in the treatment of mild coronavirus disease 2019. J Emerg Tradit Chin Med. 2020;29:756-8.

25. Yang MB, Dang SS, Huang S, Li YJ, Guo YL. Multi-center clinical observation of Reyanning mixture in treatment of COVID-19. Chin J Exp Tradit Med Formulae. 2020;26:7-12.

26. Zhou S, Feng J, Xie Q, Huang T, Xu X, Zhou D, et al. Traditional Chinese medicine Shenhuang granule in patients with severe/critical COVID-19: a randomized controlled multicenter trial. Phytomedicine. 2021;89:153612.

27. Ma Q, Xie Y, Wang Z, Lei B, Chen R, Liu B, et al. Efficacy and safety of ReDuNing injection as a treatment for COVID-19 and its inhibitory effect against SARS-CoV-2. J Ethnopharmacol. 2021;279:114367.

28. Ni L, Wen Z, Hu X, Tang W, Wang H, Zhou L, et al. Effects of Shuanghuanglian oral liquids on patients with COVID-19: a randomized, open-label, parallel-controlled, multicenter clinical trial. Front Med. 2021;15:704-17.

29. Wang JB, Wang ZX, Jing J, Zhao P, Dong JH, Zhou YF, et al. Exploring an integrative therapy for treating COVID-19: a randomized controlled trial. Chin J Integr Med. 2020;26:648-55.

30. Xu X, Zhang J, Zheng W, Yang Z, Zhao X, Wang C, et al. Efficacy and safety of reduning injection in the treatment of COVID-19: a randomized, multicenter clinical study. Ann Palliat Med. 2021;10:5146-55.

31. Hu K, Guan WJ, Bi Y, Zhang W, Li L, Zhang B, et al. Efficacy and safety of Lianhuaqingwen capsules, a repurposed Chinese herb, in patients with coronavirus disease 2019: a multicenter, prospective, randomized controlled trial. Phytomedicine. 2021;85:153242.

32. Ai XY, Luo C, Lin LP, Xie M, Fang HM, Tan XH. Therapeutic effect of integrated traditional Chinese and western medicine on COVID-19 in Guangzhou. China Trop Med. 2020;20:746-50.

33. Wang LQ, Li WN, Huang W, Zhou ZM, Deng YL, Hu YL, et al. Clinical study of Gegen Qinlian pill in treating COVID-19. Mod Tradit Chin Med Materia Medica World Sci Technol. 2020;22:3509-14.

34. Zheng ZZ, Bai ZG, Li CJ, Ge SP, Luo Y, He GD. Observation on the effect of TCM syndrome differentiation and treatment for COVID-19. Med J Commun. 2020;34:117-8.

35. Ding XJ, Zhang Y, He DC, Zhang MY, Tan YJ, Yu AR, et al. Clinical effect and mechanism of Qingfei Touxie Fuzheng recipe in the treatment of COVID-19. Herald of Medicine. 2020;39:640-4.

36. Liao GR. Efficacy and safety of Chinese herbal decoction in patients with COVID-19. Int Inf Dis. 2020:9:353. 
37. Zheng WJ, Guan JW. Clinical observation of sodium tanshinone ii A sulfonate in the treatment of COVID-19. World Latest Med Inf. 2020;20:267-8.

38. Shi SF, Fang ZY, Xiong K, Ye DL, Wang WM, Wu H, et al. Clinical studies of comprehensive TCM treatment to 30 cases of Qi Yin deficiency type of COVID-19 in its recovery period. Jiangsu J Tradit Chin Med. 2021;53:25-8.

39. Zhao F, Yang Z, Liu SX, Lv WZ, Lv SX, Mao MH, et al. Clinical study of Xuanfei Dayu decoction in treating the recovery stage of COVID-19. Shaanxi J Tradit Chin Med. 2020;41:846-8.

40. Tian J, Yan S, Wang H, Zhang Y, Zheng Y, Wu H, et al. Hanshiyi formula, a medicine for Sars-CoV2 infection in China, reduced the proportion of mild and moderate COVID-19 patients turning to severe status: a cohort study. Pharmacol Res. 2020;161:105127.

41. Xin S, Cheng X, Zhu B, Liao X, Yang F, Song L, et al. Clinical retrospective study on the efficacy of Qingfei Paidu decoction combined with Western medicine for COVID-19 treatment. Biomed Pharmacother. 2020;129:110500.

42. Zhang HT, Huang MX, Liu X, Zheng XC, Li XH, Chen GQ, et al. Evaluation of the adjuvant efficacy of natural herbal medicine on COVID19: a retrospective matched case-control study. Am J Chin Med. 2020:48:779-92

43. Zhang X, Xue Y, Chen X, Wu JM, Su ZJ, Sun M, et al. Effects of Tanreqing Capsule on the negative conversion time of nucleic acid in patients with COVID-19: a retrospective cohort study. J Integr Med. 2021;19:36-41.

44. Liu L, Shi F, Tu P, Chen C, Zhang M, Li X, et al. Arbidol combined with the Chinese medicine Lianhuaqingwen capsule versus arbidol alone in the treatment of COVID-19. Medicine. 2021;100:e24475.

45. Shen P, Li J, Tu S, Wu Y, Peng Y, Chen G, et al. Positive effects of Lianhuaqingwen granules in COVID-19 patients: a retrospective study of 248 cases. J Ethnopharmacol. 2021;278:114220.

46. Chen J, Lin S, Niu C, Xiao Q. Clinical evaluation of Shufeng Jiedu Capsules combined with umifenovir (arbidol) in the treatment of common-type COVID-19: a retrospective study. Expert Rev Respir Med. 2021;15:257-65.

47. Cheng DZ, Wang WJ, Li Y, Wu XD, Zhou B, Song QY. Analysis of curative effect of 51 patients with novel coronavirus pneumonia treated with Chinese medicine Lianhua Qingwen: a multicenter retrospective study. Tianjin J Tradit Chin Med. 2020;37:509-16.

48. Ji D, Feng P, Fei XY. Retrospective study of clinical efficacy of integrated traditional Chinese and western medicine in treatment of COVID-19. Shandong J Tradit Chin Med. 2020;39:645-7.

49. Yu HY, Ren XH, Qi XX, Zuo Q, Liu D. Efficacy study of Abidol, Qingfei Paidu decoction, Lianhua Qingwen capsule and Jinye Baidu granule in the treatment of mild/moderate COVID-19 in a Fangcang shelter hospital. Pharmacol Clin Chin Materia Medica. 2020;36:2-6.

50. Yao KT, Liu MY, Li X, Huang JH, Cai HB. Retrospective clinical analysis on treatment of coronavirus disease 2019 with traditional Chinese medicine Lianhua Qingwen. Chin J Exp Tradit Med Formulae. 2020;26:8-12.

51. Zhai XK, Hao SL, Ma JH, Wei GY, Song KY, Tang C, et al. Observation on clinical effect of Shufeng Jiedu capsule combined with abidol hydrochloride in treatment of COVID-19. Chin Tradit Herbal Drugs. 2020;51:1167-70.

52. Sun QG, An XD, Xie P, Jiang B, Tian JX, Yang Q, et al. Traditional Chinese medicine decoctions significantly reduce the mortality in severe and critically ill patients with COVID-19: a retrospective cohort study. Am J Chin Med. 2021:49:1063-92.

53. Wang Y, Lu C, Li H, Qi W, Ruan L, Bian Y, et al. Efficacy and safety assessment of severe COVID-19 patients with Chinese medicine: A retrospective case series study at early stage of the COVID-19 epidemic in Wuhan, China. J Ethnopharmacol. 2021;277:113888.

54. Chen G, Su W, Yang J, Luo D, Xia P, Jia W, et al. Chinese herbal medicine reduces mortality in patients with severe and critical Coronavirus disease 2019: a retrospective cohort study. Front Med. 2020;14:752-9.

55. Feng J, Fang B, Zhou D, Wang J, Zou D, Yu G, et al. Clinical effect of traditional Chinese medicine Shenhuang granule in critically ill patients with COVID-19: a single-centered, retrospective, observational study. J Microbiol Biotechnol. 2021;31:380-6.

56. Hu H, Wang K, Wang L, Du Y, Chen J, Li Y, et al. He-Jie-Shen-Shi decoction as an adjuvant therapy on severe coronavirus disease 2019: a retrospective cohort and potential mechanistic study. Front Pharmacol. 2021;12:700498.

57. Yang Q, Sun QG, Jiang B, Xu HJ, Luo M, Xie P, et al. Retrospective clinical study on treatment of COVID-19 patients with integrated traditional Chinese and western medicine. Chin Tradit Herb Drugs. 2020;51:2050-4.

58. Chen L, Zhang A, Li QT, Cui Y, Yuan GD. Evaluation of clinical value of Xuebijing combined with human immunoglobulin in severe and critically ill patients with coronavirus disease 2019. Chin Crit Care Med. 2021;33:399-404.

59. Shu Z, Chang K, Zhou Y, Peng C, Li X, Cai W, et al. Add-on Chinese medicine for Coronavirus Disease 2019 (ACCORD): a retrospective cohort study of hospital registries. Am J Chin Med. 2021;49:543-75.

60. Zhang L, Zheng X, Bai X, Wang Q, Chen B, Wang H, et al. Association between use of Qingfei Paidu Tang and mortality in hospitalized patients with COVID-19: a national retrospective registry study. Phytomedicine. 2021;85:153531.

61. Ai Z, Zhou S, Li W, Wang M, Wang L, Hu G, et al. "Fei Yan No. 1" as a combined treatment for COVID-19: an efficacy and potential mechanistic study. Front Pharmacol. 2020;11:581277.

62. Hu YQ, Lu JQ, Huang J, Huang QH, Jin HH, Ma YT, et al. Clinical observation of 31 cases with COVID-19 treated with Guizhi Erchen decoction based on triple-Jiao sequential therapy. Chin Arch Tradit Chin Med. 2020;38:1-5.

63. Lian J, Zhang ShJ, Li GL, Shang D, Wang QY, Xu LS, et al. Retrospective analysis of 38 cases with coronavirus disease 2019 treated by integrated traditional Chinese and western medicine. J Tradit Chin Med. 2020;61:2126-30.

64. Wang LQ, Hu GM, Ba YM, He CX, Li WN, Zhang X. A retrospective study on the treatment of coronavirus disease 2019 with "Pneumonia No. 1" combined with conventional western medicine. J Emerg Tradit Chin Med. 2021;30:10-2.

65. Shi J, Yang ZG, Ye C, Chen SS, Lu YF, Lv Y, et al. Clinical observation on 49 cases of non-critical COVID-19 in Shanghai treated by integrated traditional Chinese and western medicine. Shanghai J Tradit Chin Med. 2020;54:30-5.

66. Xia WG, An CQ, Zheng QJ, Zhang JX, Huang M, Wang Y, et al. Clinical observation on 34 patients with novel coronavirus pneumonia (COVID19) treated with integrated traditional Chinese and western medicine. J Tradit Chin Med. 2020;61:375-82.

67. An YW, Yuan B, Wang JC, Wang C, Liu TT, Song S, et al. Clinical characteristics and impacts of traditional Chinese medicine treatment on the convalescents of COVID-19. Int J Med Sci. 2021;18:646-51.

68. Shen X, Yin F. The mechanisms and clinical application of Traditional Chinese Medicine Lianhua-Qingwen capsule. Biomed Pharmacother. 2021:142:111998.

69. Huang K, Zhang P, Zhang Z, Youn JY, Wang C, Zhang H, et al. Traditional Chinese Medicine (TCM) in the treatment of COVID-19 and other viral infections: efficacies and mechanisms. Pharmacol Ther. 2021;225:107843.

70. Xia J, Rong L, Sawakami T, Inagaki Y, Song P, Hasegawa K, et al. Shufeng Jiedu Capsule and its active ingredients induce apoptosis, inhibit migration and invasion, and enhances doxorubicin therapeutic efficacy in hepatocellular carcinoma. Biomed Pharmacother. 2018;99:921-30.

71. Ma Q, Xie Y, Wang Z, Lei B, Chen R, Liu B, et al. Efficacy and safety of ReDuNing injection as a treatment for COVID-19 and its inhibitory effect against SARS-CoV-2. J Ethnopharmacol. 2021;28(279):114367.

72. Tao Q, Du J, Li X, Zeng J, Tan B, Xu J, et al. Network pharmacology and molecular docking analysis on molecular targets and mechanisms of Huashi Baidu formula in the treatment of COVID-19. Drug Dev Ind Pharm. 2020;46:1345-53.

73. Xia QD, Xun Y, Lu JL, Lu YC, Yang YY, Zhou P, et al. Network pharmacology and molecular docking analyses on Lianhua Qingwen capsule indicate Akt1 is a potential target to treat and prevent COVID-19. Cell Prolif. 2020;53:e12949.

74. Chen J, Wang YK, Gao Y, Hu LS, Yang JW, Wang JR, et al. Protection against COVID-19 injury by qingfei paidu decoction via anti-viral, anti-inflammatory activity and metabolic programming. Biomed Pharmacother. 2020;129:110281.

75. Mu C, Sheng Y, Wang Q, Amin A, Li X, Xie Y. Potential compound from herbal food of Rhizoma Polygonati for treatment of COVID-19 
analyzed by network pharmacology: viral and cancer signaling mechanisms. J Funct Foods. 2021;77:104149.

76. Gao LQ, Xu J, Chen SD. In silico screening of potential Chinese herbal medicine against COVID-19 by targeting SARS-CoV-2 3CLpro and angiotensin converting enzyme II using molecular docking. Chin J Integr Med. 2020;26:527-32.

77. Ge C, He Y. In silico prediction of molecular targets of astragaloside IV for alleviation of COVID-19 hyperinflammation by systems network pharmacology and bioinformatic gene expression analysis. Front Pharmacol. 2020;11:556984

78. Li X, Lin H, Wang Q, Cui L, Luo H, Luo L. Chemical composition and pharmacological mechanism of shenfu decoction in the treatment of novel coronavirus pneumonia (COVID-19). Drug Dev Ind Pharm. 2020;46:1947-59.

79. Ye M, Luo G, Ye D, She M, Sun N, Lu YJ, et al. Network pharmacology, molecular docking integrated surface plasmon resonance technology reveals the mechanism of Toujie Quwen Granules against coronavirus disease 2019 pneumonia. Phytomedicine. 2021;85:153401.

80. Li X, Qiu Q, Li M, Lin H, Cao S, Wang Q, et al. Chemical composition and pharmacological mechanism of ephedra-glycyrrhiza drug pair against coronavirus disease 2019 (COVID-19). Aging. 2021;13:4811-30.

81. Wu H, Gong K, Qin Y, Yuan Z, Xia S, Zhang S, et al. In silico analysis of the potential mechanism of a preventive Chinese medicine formula on coronavirus disease 2019. J Ethnopharmacol. 2021;275:114098.

82. Wang H, Zhang J, Lu Z, Dai W, Ma C, Xiang Y, et al. Identification of potential therapeutic targets and mechanisms of COVID-19 through network analysis and screening of chemicals and herbal ingredients. Brief Bioinform. 2021;23(1):bbab373.

83. Cai Y, Zeng M, Chen YZ. The pharmacological mechanism of Huashi Baidu Formula for the treatment of COVID-19 by combined network pharmacology and molecular docking. Ann Palliat Med. 2021;10:3864-95.

84. Wang J, Ge W, Peng X, Yuan L, He S, Fu X. Investigating the active compounds and mechanism of HuaShi XuanFei formula for prevention and treatment of COVID-19 based on network pharmacology and molecular docking analysis. Mol Divers. 2021. https://doi.org/10. 1007/s11030-021-10244-0

85. Xiao Z, Ye Q, Duan X, Xiang T. Network pharmacology reveals that resveratrol can alleviate COVID-19-related hyperinflammation. Dis Markers. 2021;2021:4129993.

86. Li Y, Chu F, Li P, Johnson N, Li T, Wang Y, et al. Potential effect of Maxing Shigan decoction against coronavirus disease 2019 (COVID-19) revealed by network pharmacology and experimental verification. J Ethnopharmacol. 2021;271:113854.

87. Du HX, Zhu JQ, Chen J, Zhou HF, Yang JH, Wan HT. Revealing the therapeutic targets and molecular mechanisms of emodin-treated coronavirus disease 2019 via a systematic study of network pharmacology. Aging. 2021;13:14571-89.

88. Niu WH, Wu F, Cao WY, Wu ZG, Chao YC, Liang C. Network pharmacology for the identification of phytochemicals in traditional Chinese medicine for COVID-19 that may regulate interleukin-6. Biosci Rep. 2021:41:BSR20202583.

89. Ren X, Shao XX, Li XX, Jia XH, Song T, Zhou WY, et al. Identifying potential treatments of COVID-19 from Traditional Chinese Medicine (TCM) by using a data-driven approach. J Ethnopharmacol. 2020;258:112932.

90. Xing Y, Hua YR, Shang J, Ge WH, Liao J. Traditional Chinese medicine network pharmacology study on exploring the mechanism of Xuebijing Injection in the treatment of coronavirus disease 2019. Chin J Nat Med. 2020;18:941-51.

91. Ruan X, Du P, Zhao K, Huang J, Xia H, Dai D, et al. Mechanism of Dayuanyin in the treatment of coronavirus disease 2019 based on network pharmacology and molecular docking. Chin Med. 2020;15:62.

92. Pan B, Fang S, Zhang J, Pan Y, Liu H, Wang Y, et al. Chinese herbal compounds against SARS-CoV-2: puerarin and quercetin impair the binding of viral S-protein to ACE2 receptor. Comput Struct Biotechnol J. 2020;18:3518-27.

93. Gao K, Song YP, Song A. Exploring active ingredients and function mechanisms of Ephedra-bitter almond for prevention and treatment of Corona virus disease 2019 (COVID-19) based on network pharmacology. BioData Min. 2020;13:19.

94. Yu MX, Song X, Ma XQ, Hao CX, Huang JJ, Yang WH. Investigation into molecular mechanisms and high-frequency core TCM for pulmonary fibrosis secondary to COVID-19 based on network pharmacology and data mining. Ann Palliat Med. 2021;10:3960-75.

95. Benton DJ, Wrobel AG, Xu P, Roustan C, Martin SR, Rosenthal PB, et al. Receptor binding and priming of the spike protein of SARS-CoV-2 for membrane fusion. Nature. 2020:588:327-30.

96. Chan KK, Dorosky D, Sharma P, Abbasi SA, Dye JM, Kranz DM, et al. Engineering human ACE2 to optimize binding to the spike protein of SARS coronavirus 2. Science. 2020;369:1261-5.

97. Zhang L, Lin D, Sun X, Curth U, Drosten C, Sauerhering L, et al. Crystal structure of SARS-CoV-2 main protease provides a basis for design of improved alpha-ketoamide inhibitors. Science. 2020;368:409-12.

98. Gao Y, Yan L, Huang Y, Liu F, Zhao Y, Cao L, et al. Structure of the RNA-dependent RNA polymerase from COVID-19 virus. Science. 2020:368:779-82.

99. Rut W, Lv Z, Zmudzinski M, Patchett S, Nayak D, Snipas SJ, et al. Activity profiling and crystal structures of inhibitor-bound SARS-CoV-2 papainlike protease: a framework for anti-COVID-19 drug design. Sci Adv. 2020;6:eabd4596.

100. Robson F, Khan KS, Le TK, Paris C, Demirbag S, Barfuss P, et al. Coronavirus RNA proofreading: molecular basis and therapeutic targeting. Mol Cell. 2020;79:710-27.

101. Mehta P, MCAuley DF, Brown M, Sanchez E, Tattersall RS, Manson JJ, et al. COVID-19: consider cytokine storm syndromes and immunosuppression. Lancet. 2020;395:1033-4.

102. Garbers C, Heink S, Korn T, Rose-John S. Interleukin-6: designing specific therapeutics for a complex cytokine. Nat Rev Drug Discov. 2018:17:395-412.

103. Jones HD, Crother TR, Gonzalez-Villalobos RA, Jupelli M, Chen S, Dagvadorj J, et al. The NLRP3 inflammasome is required for the development of hypoxemia in LPS/mechanical ventilation acute lung injury. Am J Respir Cell Mol Biol. 2014;50:270-80.

104. Jaco I, Annibaldi A, Lalaoui N, Wilson R, Tenev T, Laurien L, et al. MK2 phosphorylates RIPK1 to prevent TNF-induced cell death. Mol Cell. 2017:66:698-710.

105. Jordan S, Tung N, Casanova-Acebes M, Chang C, Cantoni C, Zhang D, et al. Dietary intake regulates the circulating inflammatory monocyte pool. Cell. 2019;178:1102-14.

106. Ramasamy S, Subbian S. Critical determinants of cytokine storm and type I interferon response in COVID-19 pathogenesis. Clin Microbiol Rev. 2021;34:e00299.

107. Dai W, Bi J, Li F, Wang S, Huang X, Meng X, et al. Antiviral efficacy of flavonoids against enterovirus 71 infection in vitro and in newborn mice. Viruses. 2019;11:625.

108. Tutunchi H, Naeini F, Ostadrahimi A, Hosseinzadeh-Attar MJ. Naringenin a flavanone with antiviral and anti-inflammatory effects: a promising treatment strategy against COVID-19. Phytother Res. 2020;34:3137-47.

109. Dai SJ, Ren Y, Shen L, Zhang DW. New alkaloids from Forsythia suspensa and their anti-inflammatory activities. Planta Med. 2009;75:375-7.

110. Hsu DZ, Liu MY. Bicuculline methiodide attenuates hepatic injury and decreases mortality in septic rats: role of cytokines. Shock. 2004:22:347-50.

111. Li Y, Yao J, Han C, Yang J, Chaudhry MT, Wang S, et al. Quercetin, inflammation and immunity. Nutrients. 2016;8:167.

112. Li Y, Meng T, Hao N, Tao H, Zou S, Li M, et al. Immune regulation mechanism of Astragaloside IV on RAW264.7 cells through activating the NF-kappaB/MAPK signaling pathway. Int Immunopharmacol. 2017:49:38-49.

113. Kim B, Kim YS, Hwang YH, Yang HJ, Li W, Kwon EB, et al. Quercus acuta Thunb. (Fagaceae) and its component, isoquercitrin, inhibit HSV-1 replication by suppressing virus-induced ROS production and NF-kappaB activation. Antioxidants. 2021;10:1638.

114. Ninfali P, Antonelli A, Magnani M, Scarpa ES. Antiviral properties of flavonoids and delivery strategies. Nutrients. 2020;12:2534.

115. Bai SK, Lee SJ, Na HJ, Ha KS, Han JA, Lee H, et al. beta-Carotene inhibits inflammatory gene expression in lipopolysaccharide-stimulated macrophages by suppressing redox-based NF-kappaB activation. Exp Mol Med. 2005;37:323-34. 
116. Leu WJ, Chen JC, Guh JH. Extract from Plectranthus amboinicus inhibit maturation and release of interleukin 1 beta through inhibition of NF-kappaB nuclear translocation and NLRP3 inflammasome activation. Front Pharmacol. 2019;10:573.

117. Lai JL, Liu YH, Liu C, Qi MP, Liu RN, Zhu XF, et al. Indirubin inhibits LPSinduced inflammation via TLR4 abrogation mediated by the NF-KB and MAPK signaling pathways. Inflammation. 2017;40:1-12.

118. Sithisarn P, Michaelis M, Schubert-Zsilavecz M, Cinatl J Jr. Differential antiviral and anti-inflammatory mechanisms of the flavonoids biochanin A and baicalein in $\mathrm{H} 5 \mathrm{~N} 1$ influenza A virus-infected cells. Antiviral Res. 2013:97:41-8.

119. Ma R, Yuan F, Wang S, Liu Y, Fan T, Wang F. Calycosin alleviates ceruleininduced acute pancreatitis by inhibiting the inflammatory response and oxidative stress via the p38 MAPK and NF-kappaB signal pathways in mice. Biomed Pharmacother. 2018;105:599-605.

120. Sertie JA, Basile AC, Panizza S, Matida AK, Zelnik R. Anti-inflammatory activity and sub-acute toxicity of artemetin. Planta Med. 1990;56:36-40.

121. Chu Y, Lv X, Zhang L, Fu X, Song S, Su A, et al. Wogonin inhibits in vitro herpes simplex virus type 1 and 2 infection by modulating cellular NFkappaB and MAPK pathways. BMC Microbiol. 2020:20:227.

122. Shrimali D, Shanmugam MK, Kumar AP, Zhang J, Tan BK, Ahn KS, et al. Targeted abrogation of diverse signal transduction cascades by emodin for the treatment of inflammatory disorders and cancer. Cancer Lett. 2013:341:139-49.

123. He S, Tian J, Li X, Zhou Y, Xiao M, Zhang Y, et al. Positive RT-PCR test results in 420 patients recovered from COVID-19 in Wuhan: an observational study. Front Pharmacol. 2020;11:549117.

\section{Publisher's Note}

Springer Nature remains neutral with regard to jurisdictional claims in published maps and institutional affiliations.

- fast, convenient online submission

- thorough peer review by experienced researchers in your field

- rapid publication on acceptance

- support for research data, including large and complex data types

- gold Open Access which fosters wider collaboration and increased citations

- maximum visibility for your research: over $100 \mathrm{M}$ website views per year

At BMC, research is always in progress.

Learn more biomedcentral.com/submissions 